\title{
EFFECTS OF FIVE GREEN INHIBITORS OF CONTROLLING BARITE CRYSTAL GROWTH IN FLOW-INDUCED VIBRATION IN PIPE
}

\author{
N. Karaman ${ }^{1}$, W. Mangestiyono ${ }^{2}$, S. Muryanto ${ }^{3}$, J. Jamari ${ }^{4}$ \\ and A. P. Bayuseno ${ }^{4}$, \\ ${ }^{1}$ Department of Chemical Engineering, Universitas Pembangunan Nasional Veteran, \\ Surabaya, Indonesia \\ ${ }^{2}$ Mechanical Engineering, School of Vocational, Diponegoro University, Semarang, Indonesia \\ ${ }^{3}$ Department of Chemical Engineering, UNTAG University, Semarang, Indonesia \\ ${ }^{4}$ Department of Mechanical Engineering, Diponegoro University, Semarang, Indonesia \\ *E-mail:apbayuseno@gmail.com
}

\begin{abstract}
The paper presents results on the experimental work of crystallization and prevention of barium sulfate scaling in the vibrated pipes with flowing water and the use of green chemical inhibitors. The duplicate scaling experiments were performed on the water flowing in pipes under mechanical vibration with varying frequency $(0,4$, and $8 \mathrm{~Hz})$. The result shows an increase in vibration frequency, leading to an increasing scale deposition rate. Five green inhibitors were examined, namely; formic acid; EDTA; tartaric acid; oxalic acid and acetic acid. Under the influence of vibration, the scale retardation capability of inhibitors could be presented consecutively: formic acid; EDTA; tartaric acid; oxalic acid and acetic acid. In particular, at $8 \mathrm{~Hz}$ frequency, the best scale retardation was obtained with 10 ppm of formic acid addition. The barite crystal scale was formed on pipes as confirmed by XRPD (X-ray powder diffraction) method, whereas a rosette-shaped like morphology could be developed in the crystal as observed by SEM. Additionally, the crystal surface of barite has changed to be smoother, when the frequency of vibration increased. This finding of the study is expected to add knowledge of barite scale formation in the vibrated piping system and the use of chemical additives for the scale growth prevention.
\end{abstract}

Keywords: Mechanical Vibration, XRPD Analysis, SEM Analysis, Barite, Green Chemical Inhibitors

(C) RASĀYAN. All rights reserved

\section{INTRODUCTION}

Scaling of barium sulfate (barite) frequently grows on the surface of the industrial component such as heat exchanger, condenser, and pipes existing in a wide range of oil drilling processes. ${ }^{1-3}$ The scale formation occurs when two incompatible waters with a high/low concentration of $\mathrm{SO}_{4}^{-2}$ and a low/high concentration of $\mathrm{Ba}^{+2}$ interact each other, leading to the high risk posed by the growth of barium sulfate mineral. ${ }^{3,4}$ In the offshore oil process, the barite scale could be formed due to the injection seawater containing barium ions, which is commonly used for a high-temperature lubricant and subsequently react to sulfate ions arising from the wellbore. ${ }^{4,5}$ In this way, the presence of scale eventually brings an adverse influence on the oil production, ${ }^{6,7}$ and often makes the disturbance of the processes ${ }^{8}$ due to the reduction of flow rates. This condition also contributes to an unscheduled shutdown ${ }^{9,10}$ and sometimes causes industrial instrumentation damages. ${ }^{11}$

In contrast to the ordinary scales (i.e. calcium carbonate and calcium sulfate), barite is less soluble than calcium carbonate and its solubility is $\mathrm{pH}$ independence. However, barite is more soluble with increasing the water temperature. ${ }^{6,7}$ In fact, barite scale accumulated on the surface of pipes or tube is hard to remove, whereas to remove it is very costly. The pipe is frequently injected with water for scale removal, instead of scale prevention with a chemical additive. Now, the use of chemical additives has been a common method for preventing the barite scale formation, and become intensive research in the water system and reverse osmosis applications.

Rasayan J. Chem., 12(4), 1734-1743(2019)

http://dx.doi.org/10.31788/RJC.2019.1245380

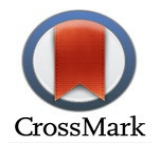


On the other hand, a piping system is usually operating under the influence of vibration which potentially affects the performance of this system. ${ }^{12,13}$ Additionally, the vibration would be a serious problem if the high-frequency vibration arises in the mechanical system. In more cases, unbalanced components and misalignment shaft may be the main source of oscillation. Moreover, the vibration potential propagates on pipes with flowing water, which is also suggested to control the scale formation, while at the same time the chemical reaction among ions may undergo in the solution.

In particular, the mechanism of scale formation under the influence of vibration may relate a hydrodynamic interaction of the water. Some mechanical forces may contribute to generating vibration in the solution. Therefore, an increase in the hydrodynamic forces may drive the scale deposited on the pipe surface, ${ }^{13}$ while at the same time, the chemical inhibitors can be employed for preventing the scale formation. In general, there is no doubt that carboxylic acids could be effective as scale inhibitors, however, they may not automatically work on every water system. ${ }^{14}$ There may be more than one type of impurities involved in the deposits. Here the main mechanism process in the barite scaling may involve crystallization (or precipitation), particulate, chemical reaction, corrosion, and biological fouling. ${ }^{15-18}$ Correspondingly, there is a need for examining the capabilities of scale inhibitors precisely and how they work or which factors sometimes prevent them from their working.

Further, a number of carboxylates have been used as the chemical inhibitor for preventing scaling of the calcium sulfate. ${ }^{14}$ The mechanism of the acid for inhibiting the scale was reported due to the acid adsorption to the crystal surface, thereby reducing the crystallization rate and changing of the crystal morphology. ${ }^{16}$ Here, the number of carboxylate form is capable to control the calcium ions and to distort the crystal lattice, leading to retard scale formation. ${ }^{14,17}$ Consequently, the strength of molecular bonding in the acid involves the energy of association and dissociation for undergoing the chemical reaction. ${ }^{18}$ Because of its atomic size, an inhibitor with a higher molecular weight is suggested to be difficult to incorporate into the crystal lattice. ${ }^{19}$ This means that the density of the acid also takes a role to scale growth retardation. Additionally, the physical properties of the acid have a strong relationship with the capability of inhibiting scale formation. This result also suggested that the use of carboxylate is much better for inhibiting the barite scale formation. Correspondingly, an understanding of the growth of barite crystal, its mechanism and morphology formed in the complex wastewater system under influence of vibration and chemical inhibitor needs precipitation experiments in addition to material characterization of the solid product.

The current research was undertaken to examine and prevent the barite scale formation by the use of five green inhibitors under influence of the vibrated piping system. In this work, five green inhibitors were selected in an attempt to prevent barite scale formation, i.e. formic acid; EDTA; tartaric acid; oxalic acid and acetic acid. Those inhibitors were chosen because they are organic acids and have also been known as environmentally friendly additives. Experimental and analytical based laboratory methods such as X-ray powder diffraction (XRPD); Fourier Transform Infra-Red spectroscopy (FTIR) and Scanning Electron Microscopy (SEM) were adopted in the experiments. These findings are expected to provide technical insight for controlling morphology and subsequent prevention of the barite scale.

\section{EXPERIMENTAL}

\section{Barite Crystal Forming Solutions}

In the study, the prepared solution for synthesizing barite consisted of barium chloride $\left(\mathrm{BaCl}_{2}\right)$ and sodium sulfate $\left(\mathrm{Na}_{2} \mathrm{SO}_{4}\right)$ reagents (Merck®), which were dissolved separately in the distilled water. Here $500 \mathrm{ml}$ of $0.35 \mathrm{M} \mathrm{BaCl}_{2}$ and $0.35 \mathrm{M} \mathrm{Na}_{2} \mathrm{SO}_{4}$ were prepared accordingly. This concentration was chosen randomly by considering the threshold of solubility barite in water $(0.220 \mathrm{M})$. The prepared liquid was then separated out using a paper filter of $0.22 \mu \mathrm{m}$-Micropore and kept in a covered container to protect from dust and other dirt material. The solution of the vessel was considered not to react to each other when the solution was added by five green inhibitors, i.e. formic acid $\left(\mathrm{CH}_{2} \mathrm{O}_{2}\right)$; EDTA $\left(\mathrm{C}_{10} \mathrm{H}_{16} \mathrm{~N}_{2} \mathrm{O}_{8}\right)$; tartaric acid $\left(\mathrm{C}_{4} \mathrm{H}_{6} \mathrm{O}_{6}\right)$; oxalic acid $\left(\mathrm{C}_{2} \mathrm{H}_{2} \mathrm{O}_{4}\right)$ and acetic acid $\left(\mathrm{C}_{2} \mathrm{H}_{4} \mathrm{O}_{2}\right)$, given in Table-1 and it must be stable enough when the solution was heated at a certain temperature. Chemical inhibitors were set at 0,5 and $10 \mathrm{ppm}(\mathrm{mg} / \mathrm{l})$ and diluted separately to the sulphate solution for each experiment. Barite precipitation 
occurs when $\mathrm{BaCl}_{2}$ and $\mathrm{Na}_{2} \mathrm{SO}_{4}$ solution meets in the house of coupon according to the reaction in equation (1).

\begin{tabular}{c|c|c|c|c}
\multicolumn{2}{c}{$\mathrm{BaCl}_{2}(\mathrm{aq})+\mathrm{Na}_{2} \mathrm{SO}_{4}(\mathrm{aq}) \rightarrow \mathrm{BaSO}_{4}(\mathrm{~s})+2 \mathrm{NaCl}(\mathrm{aq})$} \\
Table-1: Properties of Inhibitor Utilized in the Experiments
\end{tabular}

\section{Equipment Used for the Experiments}

Experiments were conducted using a scale formation simulator, which was equipped with a computer program control. The experimental simulator is schematically shown in Fig.-1. Two vessels containing $\mathrm{BaCl}_{2}$ and $\mathrm{Na}_{2} \mathrm{SO}_{4}$ solution were employed, and the vessel was equipped with a stirrer to ensure the solution mixed homogeneously. Subsequently, each solution was pumped and flows vertically from the bottom. An electrical heater was placed in the solution, on which the temperature could be monitored and adjusted as the requirement. A dosing pump (CHEM FEED Ca-92683) was employed to circulate the solution with a flow rate of $30 \mathrm{ml} / \mathrm{min}$. Further, the test pipe section is equipped with four pairs of copper coupons on which the coupon is set up parallel with the flow and the scale would be formed. The tube was tied along with a table and the table was vibrated reciprocally by a mechanical system comprising an electrical motor, crankshaft and connecting rod. The computer program sets the electric motor in a certain rotation for the vibration frequency (i.e. $0.00 ; 4.00$ and $8.00 \mathrm{~Hz}$ ). To record the vibration parameter such as displacement and acceleration uses Vibrometer Lutron (VT-8204). It was proposed here that the vibration of the flow has the same frequency of the vibrated piping. In particular, the mechanical vibration of a pipeline containing fluid flow could significantly contribute to the energy in the flow, which was converted into dynamic pressure near the wall. The dependency between pipe vibration and fluid flow on barite crystal growth was examined for producing mass and morphological type of scale, whereas the flow-induced vibration of the pipeline is likely to control the barite scale formation on the coupon.

After running for $4 \mathrm{~h}$, the apparatus was switched off and the coupon containing scale was removed for subsequent drying in an oven at $60{ }^{\circ} \mathrm{C}$ for $6 \mathrm{~h}$. The obtained scale was then weighed using analytical balance (Ohaus AR-2140). Subsequently, the dried scale was removed from the coupon or strainer and labeled as an experimental parameter. In this study, the duplicate experiments were carried out to assure repeatability and the obtained values during the experiments were averaged for the analysis.

\section{Materials Characterization}

X-ray powder diffraction (XRPD) technique with a conventional Bragg-Brentano part focusing geometry (Rigaku SmartLab X-Ray Diffractometer) and $\mathrm{Cu}-\mathrm{K} \alpha$ monochromated radiation were employed to 
measure the precipitate. The obtained XRPD data were then identified for crystalline phases using a PCbased search match program.

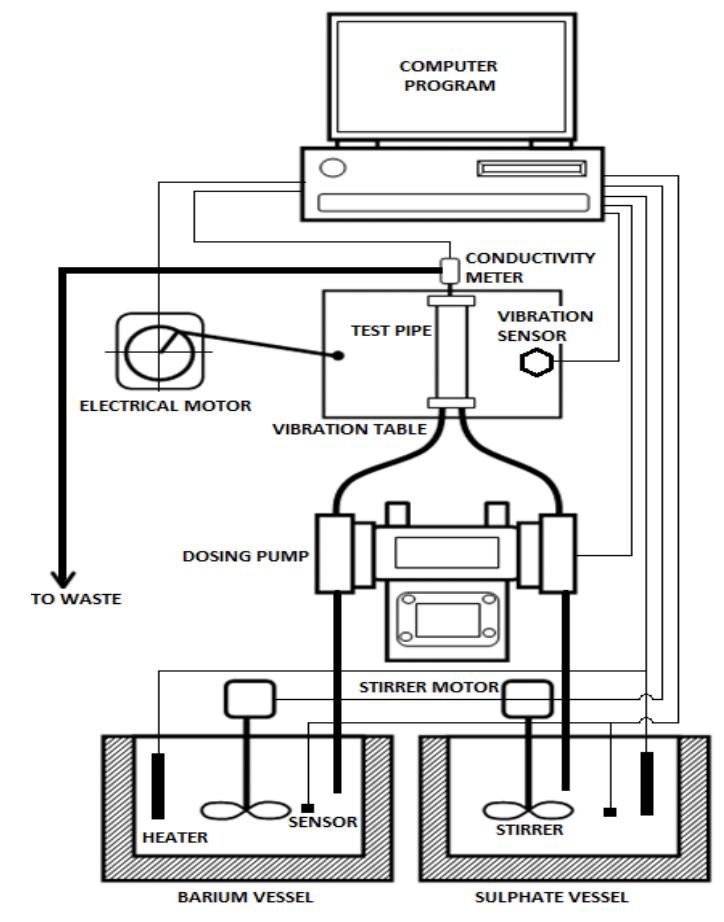

Fig.-1: Experimental Equipment used for the Study

In this way, the line positions of the peaks were searched and matched with the data of the International Centre for Diffraction Data-Powder Diffraction File (ICDD-PDF). Moreover, the identified phase was then validated by the Rietveld refinement technique using FullProf-2k software version 3.30. For the Rietveld refinement, the crystal structure model was obtained in the literature of American Mineralogist crystal structure database (AMCSD) ${ }^{20}$. Additionally, the morphology of scale precipitated was observed with SEM/EDX (FEI Inspect S50) at a voltage of $20 \mathrm{kV}$. SEM images were acquired using a Mega view III digital camera (EMSIS GmbH). Prior to SEM analysis, samples were mounted on a circular Al-holder and finally sputtered to the surface with carbon.

\section{RESULTS AND DISCUSSION \\ Effect of Vibration Frequency on the Scale Deposition Rate}

Scale obtained on the coupon after 4-h experiments were examined in the study. An analytical balance (Ohaus AR21040) was used for weighing scale mass. The results of the scale deposited in the coupon under the influence of varying vibration frequency are presented in Table-2. In the absence of vibration, the scale deposit of $1.3469 \mathrm{~g} \cdot \mathrm{m}^{-2} \cdot \mathrm{h}^{-1}$ was obtained and subsequently increased to $1.3875 \mathrm{~g} \cdot \mathrm{m}^{-2} \cdot \mathrm{h}^{-1}$ and $1.6362 \mathrm{~g} . \mathrm{m}^{-2} \cdot \mathrm{h}^{-1}$, when the vibration frequency was increased from 4 and $8 \mathrm{~Hz}$. Presumably, the increased rotation speed of the cylinder electrode from $1000 \mathrm{rpm}$ to $3000 \mathrm{rpm}$ promoted the energy force at the wall pipe controlling the scale deposition ${ }^{15}$. A possible explanation of increasing in scale deposition may relate to nucleation during the first step of precipitation (either homogenous or heterogeneous mechanism) on the pipe surface. When a critical amount of crystallization nuclei had been formed, then the rapid process of the barite crystal growth occurred on the nucleus surface.

\section{Influence of Inhibitors on the Crystal Growth}

Besides flow induced by pipe vibration, chemical additives may also play a role in the prevention of barite crystal growth. Table-2 presents the experimental results of the impacts of a chemical inhibitor on barite scale precipitation. The experiments with additives were performed only under the influence of 8 
$\mathrm{Hz}$ frequency. This condition was chosen because the only significant reduction in the scale deposition could be discovered. The use of formic acid made reduction in the scale deposition rate (from $1.6362 \mathrm{~g} . \mathrm{m}^{-}$ ${ }^{2} \cdot \mathrm{h}^{-1}$ to $\left.1.4920 \mathrm{~g} \cdot \mathrm{m}^{-2} \cdot \mathrm{h}^{-1}\right)$. However, an increased additive of from $5 \mathrm{ppm}$ and $10 \mathrm{ppm}$ lead to reducing the precipitation rate of $1.4920 \mathrm{~g} \cdot \mathrm{m}^{-2} \cdot \mathrm{h}^{-1}$ to $1.4233 \mathrm{~g} \cdot \mathrm{m}^{-2} \cdot \mathrm{h}^{-1}$. It is proposed that the carboxylate could retard very well the scale formation ${ }^{17}$. Here, among the chemical inhibitors chosen, the use of formic acid leads to the better capability for retarding the scale formation (Fig.-2).

Table-2: Scale Deposition of All Experiments

\begin{tabular}{|c|c|c|c|c|}
\hline \multirow[b]{2}{*}{ No } & \multirow{2}{*}{$\begin{array}{c}\text { Vibration } \\
(\mathrm{Hz})\end{array}$} & \multicolumn{2}{|c|}{ Additive } & \multirow{2}{*}{$\begin{array}{l}\text { Scale Deposited } \\
\left(\mathrm{g} \cdot \mathrm{m}^{-2} \cdot \mathrm{h}^{-1}\right)\end{array}$} \\
\hline & & Acid & (ppm) & \\
\hline 1 & 0 & - & 0 & 1.3469 \\
\hline 2 & 4 & - & 0 & 1.3875 \\
\hline 3 & 8 & - & 0 & 1.6362 \\
\hline 4 & 8 & Tartaric & 5 & 1.5007 \\
\hline 5 & 8 & Tartaric & 10 & 1.4581 \\
\hline 6 & 8 & Acetic & 5 & 1.5394 \\
\hline 7 & 8 & Acetic & 10 & 1.4852 \\
\hline 8 & 8 & Oxalic & 5 & 1.5307 \\
\hline 9 & 8 & Oxalic & 10 & 1.4775 \\
\hline 10 & 8 & EDTA & 5 & 1.5123 \\
\hline 11 & 8 & EDTA & 10 & 1.4552 \\
\hline 12 & 8 & Formic & 5 & 1.4920 \\
\hline 13 & 8 & Formic & 10 & 1.4233 \\
\hline
\end{tabular}

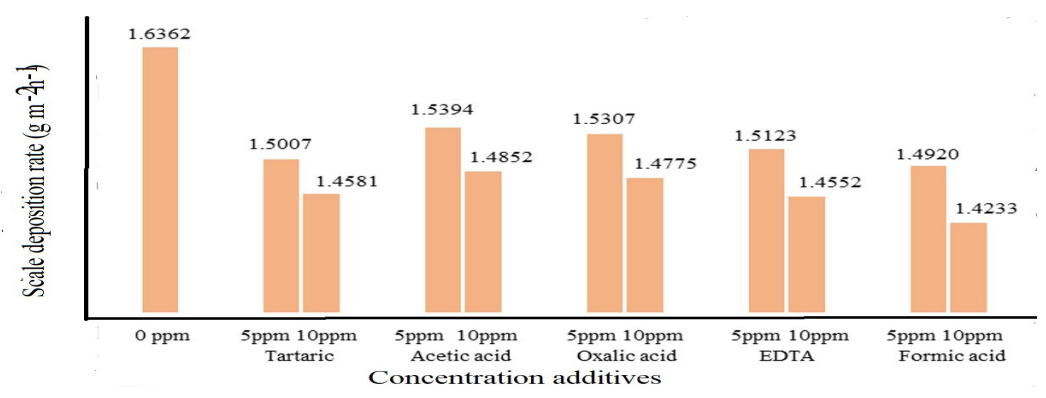

Fig.-2: Barite Scale Growth $\left(\mathrm{g} \cdot \mathrm{m}^{-2} \cdot \mathrm{h}^{-1}\right)$ resulted from the Precipitating Experiments Under Influence of $8.00 \mathrm{~Hz}$ Vibration Frequency and Five Inhibitors

According to the experimental results from different types of inhibitors evaluated in this study, EDTA is the 2nd ranked for its capability to retard the scale formation. EDTA contains more carboxyl groups per mole. On the contrary, tartaric acid, oxalic acid, and acetic acid are considerably less sensitive to the retardation of barite crystal growth. It can be seen that the inhibitor capability has a solid relationship with the physical properties such as density and number of carboxylate, but the acidity and their standard enthalpies have an insignificant impact on inhibitor performance. It seems that the inhibitor with a higher molecular weight could be difficult to incorporate into the lattice. ${ }^{19}$ In this study, the formic acid and EDTA having the smallest density, are proposed for the best inhibitor for the barite scale formation. Importantly, the density of acid predominates the ability in retarding the scale than carboxylate number. The influence of acidity and enthalpies of the chemical inhibitor on the scale retardation might be subsequently confirmed by the FTIR analysis.

\section{Morphological Investigation of the Precipitating Solid}

SEM analysis was used to investigate the eight distinct barite morphologies from experimental results of no additive-no vibration; no additive-vibrated and additives-vibrated pipe experiments (Fig.-3). Crystal morphologies resulted from experiments with no additive- no vibrated and no additive-vibrated pipes (Figures 3a,b, and c) show a small difference in their sizes. However, the morphologies of no additive- 
vibrated experiments have the mostly thinner size and hence the flow-induced vibration affected the crystal growth leading to becoming denser than that formed under no vibration condition. Moreover, crystals of no additive-vibrated experiment have a smoother surface than that of no vibration crystal. This result may be contributed by the hydrodynamic force driving the crystal growth. This untextured crystal's surface reveals that hydrodynamic force function as the promoter.
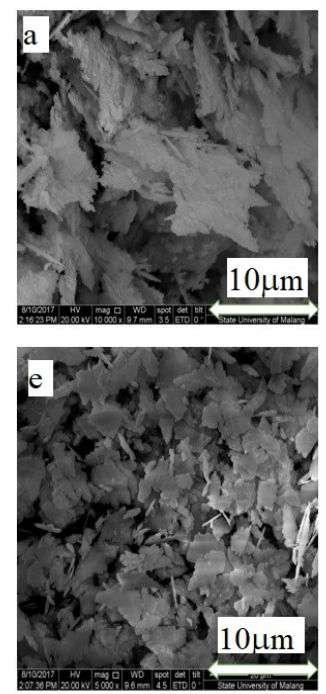
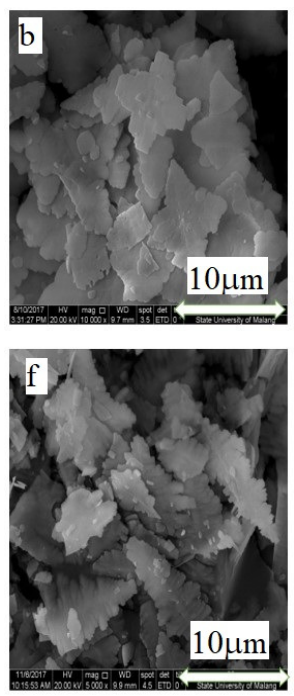
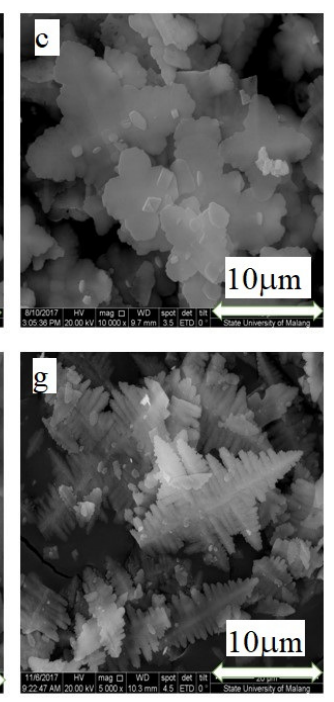
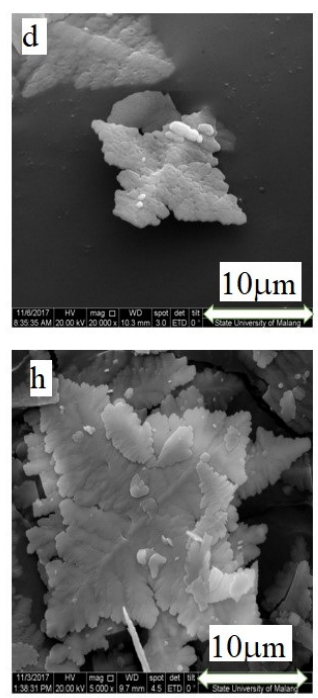

Fig.-3: Morphologies of Barite Resulted from the Solution with; (a) No Additive-No Vibration; (b) No AdditiveVibrated at $4 \mathrm{~Hz}$; (c) No Additive- Vibrated at $8 \mathrm{~Hz}$; (d) Formic Acid- Vibrated at $8 \mathrm{~Hz}$; (e) EDTA- Vibrated at 8 $\mathrm{Hz}$; (f) Tartaric Acid-Vibrated at $8 \mathrm{~Hz}$; (g) Oxalic Acid-Vibrated at $8 \mathrm{~Hz}$; (h) Acetic Acid-Vibrated at $8 \mathrm{~Hz}$ Experiments

Further morphologies of barite scale in the presence of inhibitors could be examined from SEM micrographs of samples (Fig.-3d,e,f,g, and h) resulted from the addition of formic acid; EDTA; tartaric acid; oxalic acid and acetic acid respectively. All experiments were conducted at the temperature of $35{ }^{\circ} \mathrm{C}$, while the inhibitor concentration of $10 \mathrm{ppm}$ and vibration frequency $8.00 \mathrm{~Hz}$ was set-up. The barite scale obtained from the addition of formic acid and EDTA (Fig.-3d and 3e) has a rosette-like shape morphology with thinner sizes, in which the lower mass was obtained as can be supported by the scale deposited data (Table-2). The formic acid and EDTA added in the solution yielded the lesser mass. It is proposed here that the formic acid and EDTA successfully retarded the scale growth, in which the yield of size crystal morphology has thinner than other crystals observed during the experiments. Correspondingly, the formic acid and EDTA are proposed in the study as good inhibitors with the least density, the least acidity, and the larger enthalpy, in which these properties could be effective for retarding the barite scale formation. ${ }^{16-19}$

Additionally, barite precipitated in the solution with the addition of tartaric acid and vibrated at $8.00 \mathrm{~Hz}$ and yielded its microstructure with the rosette and euhedral morphology (Fig.-3f). Moreover, barite with the full-rosette morphology could be precipitated in the experiments with the addition of the oxalic acid and resulted in the smaller grain size, which may grow faster in one diagonal direction (Fig.-3g). The precipitation experiment with the addition of the $10 \mathrm{ppm}$ acetic acid and a vibration frequency of $8.00 \mathrm{~Hz}$ yielded the rosette crystal having about $20 \mu \mathrm{m}$ in size (Fig.-3h). The crystal shape also shows quite dense. These results indicate that barite crystal growth may be suppressed by the interaction between carboxyl groups of additives and flow induced by vibration. This interaction may change predominantly crystal size by pre-serving growth-suppressed surfaces.

\section{XRPD Analysis of the Precipitating Solid}

The XRPD data obtained from the precipitation experiments with no additive and no vibration; no additive vibrated at $8.00 \mathrm{~Hz}$ and all five additives are presented in Fig.-4. All the X-ray diffraction profile 


\section{RASĀYAN J. Chem.}

GALLEY PROOFS

peaks could be validated by the XRPD Rietveld method and matched (Fig.-4a) with the reference of the barite crystal structure model. ${ }^{20}$ The diffraction peaks with (h k l) values for (200),(210),(211),(020),(401) and (410) were the characteristics of orthorhombic barite crystals. Moreover, only barite peaks in the XRD spectra could be identified indicating that the precipitating solid had high purity in nature (Figure 4b). The crystallite size of barite was predicted using the Debye-Scherrer formula (2). Here the crystallite size can be calculated as follows:

$$
\mathrm{D}=\frac{0.94 \lambda}{\beta \cos \theta}
$$

Where $\mathrm{D}, \lambda, \beta$ and $\theta$ are the average diameters, the $\mathrm{X}$-ray wavelength, the half-width of the peak (full width at half maximum) and the Bragg's diffraction angle respectively. The crystallite sizes of the barite were estimated for high-intensity peaks. Here the average particle size of barite was calculated to be in the range between $80-95 \mathrm{~nm}$.

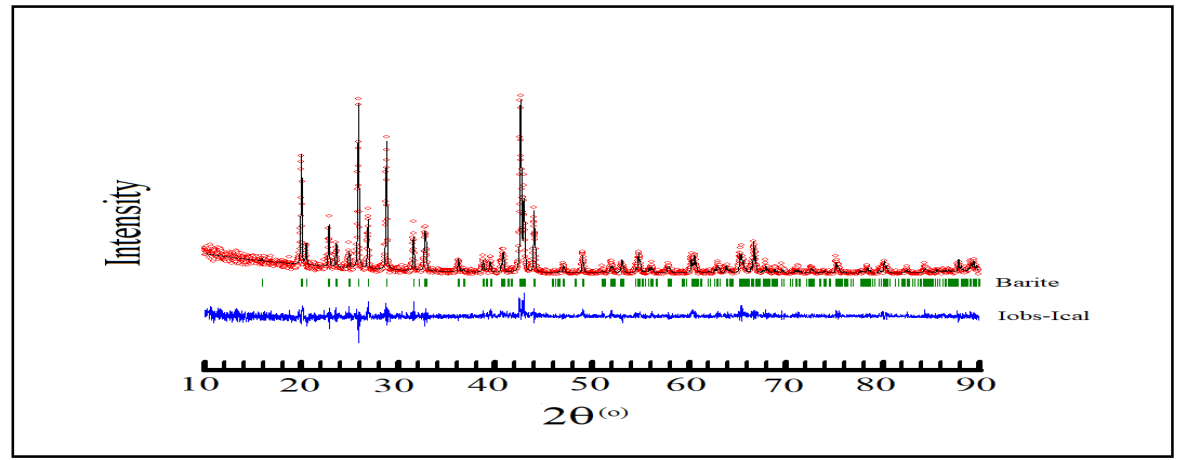

(a)

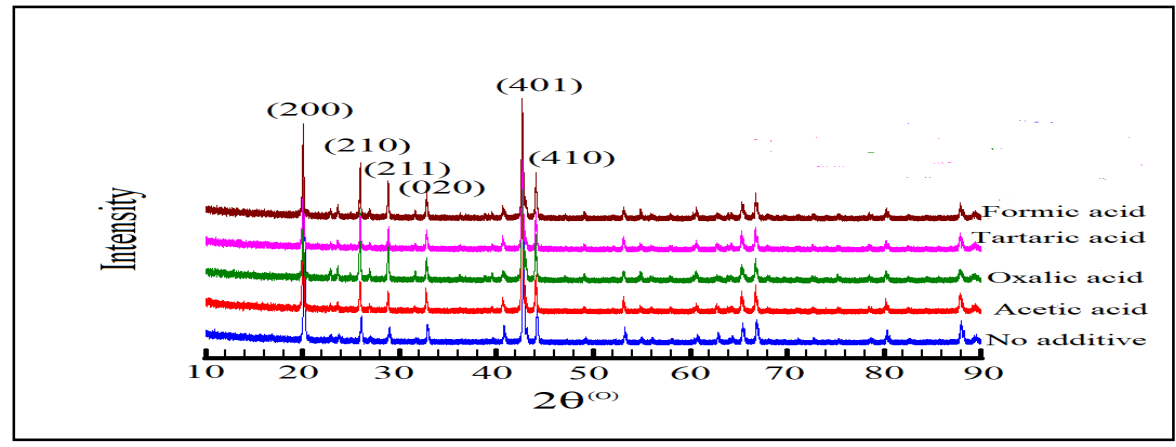

(b)

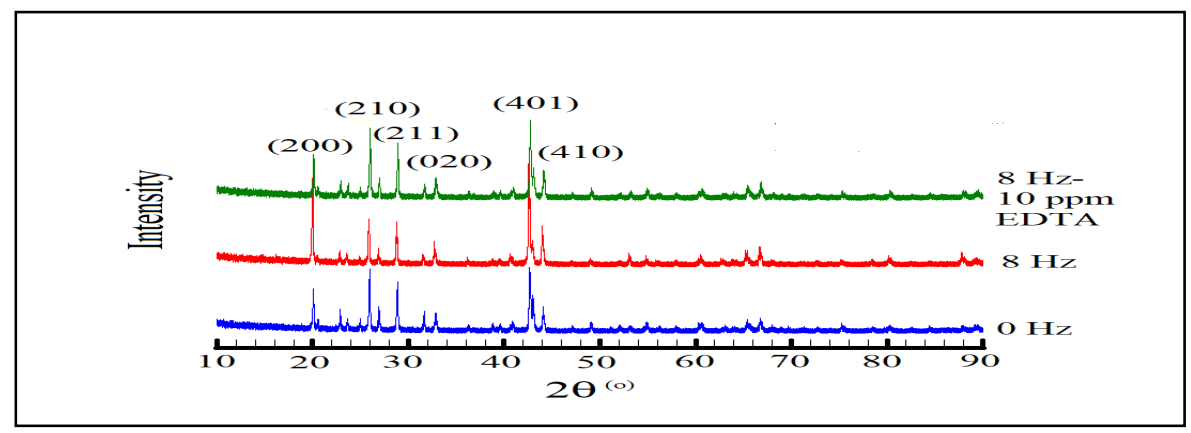

(c)

Fig.-4: (a) Plot of XRPD Rietveld Analysis of the Scale obtained from the Experiments with No Additive-Vibration;

(b) XRPD Diffractogram of all Samples with $10 \mathrm{ppm}$ and without Additives Showing All Six Distinct and Very Intense Barite Peaks [(200), (210), (211), (020), (401) and (410)]; (c) XRPD Diffractogram of All Samples with 10 ppm Addition of Formic Acid and EDTA 
Further XRPD analysis of the precipitating solids under the influence of vibration and the use of inhibitor confirmed that no change significantly the intensity of X-ray diffractogram and no phase alteration were found during the study (Fig.-4b). However, the barite crystal may be composed of any single crystal which had been formed from a solid solution. It was previously confirmed that the experiments with the addition of $10 \mathrm{ppm}$ formic acid and EDTA resulted in better retardation. Here no alteration of phases in the precipitating solids was also found by the XRPD analysis (Fig.-4c). It seems that the mechanical vibration $(8.00 \mathrm{~Hz}$ frequency) of pipes and the use of additives only modifies the size of the barite crystal, but did not significantly change its morphology. This finding is supported by the evidence that there is no significant change of XRD relative intensities as observed during the study.

\section{FTIR Analysis of the Precipitating Solid}

FTIR analysis results of seven samples are presented in one graph as shown in Fig.-5. Every spectrum has been labeled by its experiment for no vibration; vibrated pipe experiments and the use of five green inhibitors. The spectrums are also marked by its band, especially for the band that affected by the vibration and the addition of inhibitors. Here the assigned peaks of $605 \mathrm{~cm}^{-1}$ and $646 \mathrm{~cm}^{-1}$ relate to the sharp bending vibration bands of $\mathrm{Ba}_{-} \mathrm{SO}_{4}{ }^{-2} \cdot{ }^{21,22}$ In the vibrated experiments, those two peaks split into three peaks because the hydrodynamic force controlled the reaction which justifies that $\mathrm{BaSO}_{4}$ formation undergoes in the higher dynamic flow induced by the mechanical vibration. In the reaction under the influence of EDTA, however, those peaks are shown in shorter because of the appearing new peak of $1404 \mathrm{~cm}^{-1}$ which assigned as the COO symmetric vibration of carboxylate forms. ${ }^{2}$ Appearance $1404 \mathrm{~cm}^{-1}$ peak normal relates to the presence of EDTA because EDTA has larger carboxylate form among others. The result also matches with data on the scale deposition rate in which the addition of EDTA in the solution resulted in fewer scale.

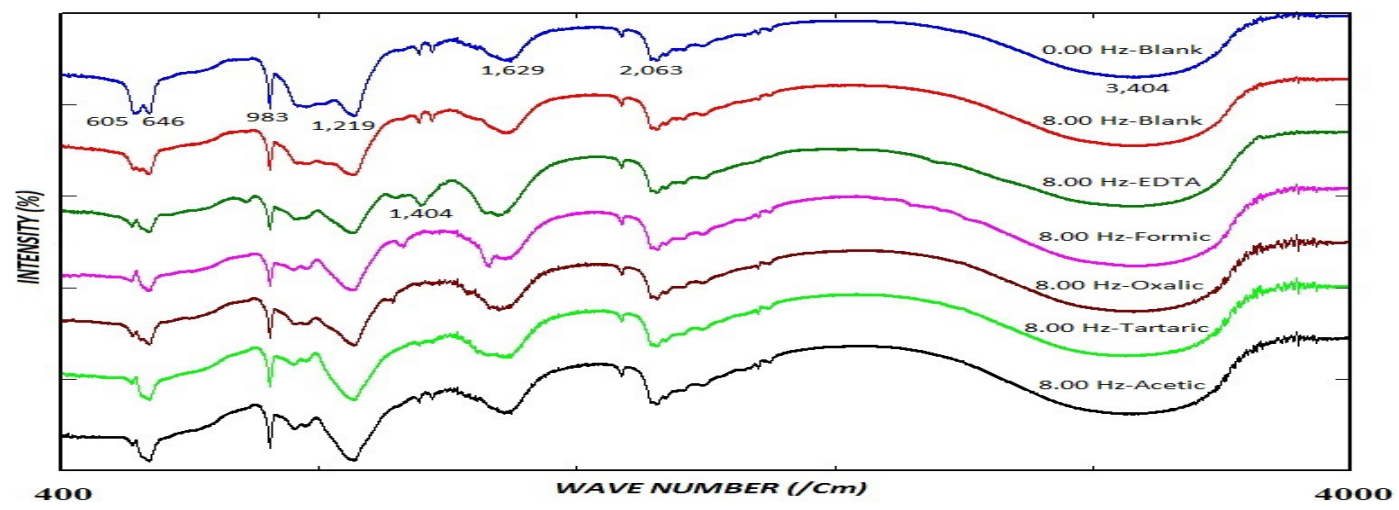

Fig.-5: FTIR Data of Scale Resulting from Precipitating Experiments with No and Five Inhibitors and Varying Frequencies of Vibration

Further to the formic acid added in the solution leads to change the peaks of $605 \mathrm{~cm}^{-1}$ and $646 \mathrm{~cm}^{-1}$ in which the clear and broad peak corresponded to the stretching band of barite in the absence of vibration. Moreover, the peak of $605 \mathrm{~cm}^{-1}$ did almost not appears anymore, in the presence of other acids. Additionally, the peak at wavenumbers of $1404 \mathrm{~cm}^{-1}$ that assigned as COO from carboxylate had appeared. In this study, the inhibition mechanism seems not to be affected by the number of carboxylates, but it might be controlled by a different mechanism. Presumably, the scale deposition could be successfully retarded using formic acid. Likewise, the use of other inhibitors such as tartaric acid, oxalic acid, and acetic acid, shows in a similar mechanism as formic acid used.

The further peak at wavenumbers of $983 \mathrm{~cm}^{-1}$ could be assigned as sharp bending vibration of $\mathrm{Ba}_{-} \mathrm{SO}_{4}{ }^{-2}{ }^{22}$ The peak is shown in similar for all experiments unless in the presence of formic acids made a significant reduction of spectra compared to that of a peak in the absence of vibration and other additives. Obviously, the impact of formic acid resulted in retarding significantly the barite scale growth. Furthermore, the peak of $1219 \mathrm{~cm}^{-1}$ is known as stretching vibration of $\mathrm{H}-\mathrm{O}-\mathrm{H}$ present in the solution. ${ }^{23}$ The $\mathrm{H}-\mathrm{O}-\mathrm{H}$ bending 
found in this experiment may relate to the water ion in barite formation $\left(\mathrm{BaSO}_{4} \cdot 2 \mathrm{H}_{2} \mathrm{O}\right)$. In addition to the peaks at wavenumbers of $1629 \mathrm{~cm}^{-1}, 2063 \mathrm{~cm}^{-1}$ and $3404 \mathrm{~cm}^{-1}$ could be also assigned as OH stretching of a water molecule. ${ }^{21,24,25}$ According to this experimental finding, the binding capacities to form complexes with barite follow the descending order of formic acid, EDTA and tartaric acid, oxalic acid and acetic acid. This conclusion is consistent with the observed effects of chemical additives on the rates of scale deposition in this study and previous findings. ${ }^{26-28}$

\section{CONCLUSION}

The use of five green inhibitors for retarding barite scale precipitation in the vibrated pipe containing solution has been successfully performed. Barite could be deposited under the influence of vibration and the resulting scale increased significantly in the presence hydrodynamic force contributed by the induced flow of pipe vibration. Among five green inhibitors added in the amount of $10 \mathrm{ppm}$, the use of formic acid resulted in better retardation in barite scale growth. Also, the inhibitory properties such as the number of carboxylates; density; acidity and the standard enthalpy control the crystal growth, in which the density predominates in retarding the scale. In this work, the pure barite was precipitated with the rosette-like morphology. Morphological investigation showed the new habit crystals in which the surface crystal of barite to be denser and smoother when the $8.00 \mathrm{~Hz}$ vibration frequency was subjected to a pipe system. This work provides technical insight for controlling barite crystal growth in the vibrated pipe using chemical additives.

\section{ACKNOWLEDGMENT}

Authors wish to express a gratitude thank to the Ministry of Research, Technology and Higher Education of the Republic of Indonesia for providing a research grant with a number: 25/UN63.8/LTKontrak/II/2018.

\section{REFERENCES}

1. M. Jamialahmadi and H. Müller-Steinhagen, Chemical Engineering Research and Design, 85(A2), 245 (2007), DOI:10.1205/cherd06050

2. F. Jones, P. Jones, M.I. Ogden, W.R. Richmond, A.L. Rohl and M. Saunders, Journal of Colloid and Interface Science, 316, 553 (2007), DOI:10.1016/j.jcis.2007.09.005

3. H.Movahedi, S. Shada and Z.B. Mokhtari-Hosseini, Journal of Petroleum Science and Engineering, 161, 476 (2018), DOI:10.1016/j.petrol.2017.12.014

4. W.J. Benston, I.R. Collins, I.M. Grimsey, G.M. Parkinson and S.A. Rodger, Faraday Discussions, 95, 281 (1993), DOI:10.1039/FD9939500281

5. K.S. Sorbie and E.J. Mackay, Journal of Petroleum Science and Engineering, 27, 85 (2000), DOI: 10.1016/S0920-4105(00)00050-4

6. Z. Amjad, Water treatment. (China Ocean Press) 9, 47 (1994)

7. L. V. L. Venâncio, A.S.F. Farinha and M.T. S. R. Gomes, Talanta 189, 65 (2018), DOI: 10.1016/j.talanta.2018.06.055

8. T.A. Hoang, H.M. Ang and A.L. Rohl, Powder Technology 179, 31, (2007), DOI: 10.1016/j.powtec.2006.11.013

9. Z. Belarbi, J. Gambya, L. Makhloufi, B. Sotta and B. Tribollet, Journal of Crystals Growth, 386, 208 (2014), DOI:10.1016/j.jcrysgro.2013.09.048

10. A. Martinod, M. Euvrard, A. Foissy and A. Neville, Desalination, 220, 345 (2008), DOI: 10.1016/j.desal.2007.01.039

11. Y.Tang, W.Yang, X. Yin, Y. Liu, P. Yin and Y. Wang, Desalination, 228, 55 (2008), DOI: 10.1016/j.desal.2007.08.006

12. K. Labiod and S. Ghizellaoui, Energy Procedia 18, 1541 (2012), DOI: 10.1016/j.egypro.2012.05.171

13. C.Ruiz-Cárcela, V.H.Jaramillo, D.Mba, J.R.Ottewill and Y.Cao, Mechanical System and Signal Processing, 66, 699 (2016), DOI: 10.1016/j.ymssp.2015.05.018

14. T. Rabizadeh, C.L. Peacock and L.G. Benning, Mineralogical Magazine, 78 (6), 1465 (2014), DOI: 10.1180/minmag.2014.078.6.13

15. P. Zhang, Z.Y. Zhang, Y. Liu, A.T. Kan, M.B. Tomson, Journal of Petroleum Science and Engineering, 172, 288 (2019), DOI: 10.1016/j.petrol.2018.09.069 
16. A. Quddus and L.M. Al-Hadhrami, Desalination 246, 526 (2009), DOI: 10.1016/j.desal.2008.11.005

17. N. Wada, K. Kanamura and T. Umegaki, Journal of Colloid and Interface Science, 233, 65 (2001), DOI: $10.1006 /$ jcis. 2000.7215

18. A. Ersen, A. Smith and T. Chotard, Journal of Materials Science, 41, 7210 (2006), DOI: 10.1007/s10853-006- 0918-6

19. R.M. Badger, Journal of Chemical Physics, 2, 128 (1934)

20. R. T. Downs and M. Hall-Wallace, American Mineralogist, 88, 247 (2003)

21. T. Chen, A. Neville, K. Sorbie and Z. Zhong, Chemical Engineering Science, 64, 912(2009), DOI: 10.1016/j.ces.2008.09.036

22. J. Manam, and S.J. Das, Journal of Alloys and Compounds, 489, 84(2010), DOI: 10.1016/j.jallcom.2009.09.018

23. M. Uchida, A. Sue, T. Yoshioka and A. Okuwaki, CrystEngComm, 3, 21(2001), DOI: 10.1039/B009571K

24. P.V. Coveney, R.J. Davey, J.L.W. Griffin, Y. He, J.D. Hamlin, S. Stackhouse and A. Whiting, Journal of the American Chemical Society, 122, 11557 (2000), DOI:10.1021/ja990885i

25. S. Sivakumar, P. Soundhirajan, A. Venkatesan and C.P. Khatiwada, Spectrochim Acta Part A: Molecular and Biomolecular Spectroscopy, 137, 137 (2015), DOI:10.1016/j.saa.2014.08.080

26. N. Patel and A. Singh, Rasayan Journal of Chemistry, 8, 2 (2015)

27. W. Mangestiyono, S. Muryanto, J. Jamari and A.P. Bayuseno, Rasayan Journal of Chemistry, 12, 192 (2019), DOI:10.31788/RJC.2019.1215055

28. S. Velrani and R. Mahalakshmi, Rasayan Journal of Chemistry, 8, 156 (2015)

[RJC-5380/2019] 